\title{
Is saliva serology useful for the diagnosis of Helicobacter pylori?
}

\author{
J M L Christie, C A M McNulty, N A Shepherd, R M Valori
}

\begin{abstract}
Background-The Cortecs Diagnostics Helisal Assay test is a quantitative immunoassay for salivary IgG antibodies against Helicobacter pylori. Saliva can be obtained simply with the kit in the general practitioners surgery.

Aims-To compare the new saliva serological test for $H$ pylori with 'gold standard' evidence of $H$ pylori infection (antral biopsy specimens for histology, culture, and urease test) and a new serum serological test.

Patients-Eighty six unselected dyspeptic patients undergoing endoscopy.

Methods-Each patient provided saliva and serum before endoscopy for $\boldsymbol{H}$ pylori serology, which was compared against 'gold standard' evidence of infection.

Results-Thirty two patients were $H$ pylori positive by the 'gold standard' tests. At a cut off value of $0.15 \mathrm{EU} / \mathrm{ml}$ the saliva test had a sensitivity of $88 \%$ and a specificity of $71 \%$, with a negative predictive value of $90 \%$. If patients who were taking omeprazole or had recent antibiotics are excluded, the sensitivity is unchanged but the specificity increases to $79 \%$. The serum test had a similar sensitivity of $85 \%$ but better specificity of $78 \%$.

Conclusion-Serum testing remains the best serological test for $H$ pylori in the hospital setting. Saliva testing may have a role in epidemiological studies and in screening dyspeptic patients in general practice, especially in children in whom venesection is more difficult.

(Gut 1996; 39: 27-30)
\end{abstract}

Keywords: Helicobacter pylori, serology, saliva.

Since Helicobacter pylori was first isolated from human gastric biopsy material in $1982,{ }^{1}$ the gold standard diagnostic test has remained histological analysis and culture of antral biopsy specimens. ${ }^{2}$ These techniques are invasive and may take $24-72$ hours, and therefore there is a need for a good serological test that would avoid the need for endoscopy. The systemic hormonal antibody response to $H$ pylori is well documented and correlates well with infection. ${ }^{3-5}$ Enzyme linked immunosorbent assay (ELISA) has been used widely in epidemiological studies and more recently for monitoring the longterm outcome of $H$ pylori therapeutic regimens. ${ }^{6}$ Sobala's proposal to perform $H$ pylori serology on all patients under 45 years referred for endoscopy reduced workload by $30 \%{ }^{7}$ Workload could be reduced further by raising the cut off to 55 years without reducing the detection of malignant disease. ${ }^{8}$ Dyspeptic patients who purchase over the counter $\mathrm{H}_{2}$ antagonists may benefit from $H$ pylori eradication rather than repeat self treatment with cimetidine. A simple serological test to assess their $H$ pylori status would therefore be very useful to general practitioners.

We evaluated a new saliva test for the diagnosis of $H$ pylori, comparing this with gold standard evidence of $H$ pylori and also with a serum serological test. The Cortecs Diagnostics Helisal Assay is a quantitative immunoassay for the measurement of salivary IgG antibodies against $H$ pylori. Saliva collection has the advantage of being a non-invasive simple test that can be easily performed in the general practice setting; collection is easy for patients and health care personnel and greatly reduces the risk of bloodborne infections.

\section{Methods}

Eighty six unselected patients undergoing endoscopy at Gloucestershire Royal Hospital for investigation of dyspepsia took part. Blood and saliva were taken prior to endoscopy. At endoscopy, three antral biopsy specimens were taken for urease test, culture, and histology. ${ }^{9}$ If any one of these 'gold standard' tests were positive, the patients were deemed $H$ pylori positive. The predictive value of the saliva test was compared with these gold standard tests, as well as a serum serological test.

The saliva was collected using an Omni-Sal collection device; this resembles an absorbent lollipop. The device is placed in the mouth for approximately 2-5 minutes. When enough saliva has been produced, the tip of the device turns from white to blue. The device is then placed into a separator tube containing buffer, and can be stored at room temperature for up to one month. All sera were stored in aliquots at $-20^{\circ} \mathrm{C}$ until assayed.

Plastic microwells coated with antigens extracted from $H$ pylori were incubated with control/standard solutions and the samples of human saliva for 30 minutes. Salivary (IgG) antibodies to $H$ pylori present in the samples become bound to antigen on the microwells. The microwells are then washed five times with working wash solution using a manual or automated plate washer $(333-500 \mu \mathrm{l} /$ well) to remove unbound material. A second incubation then takes place with biotinylated antibody to human IgG for 30 minutes. The wells are then washed as before, and a third incubation for 15 minutes with streptavidin labelled (HRP) enzyme conjugate is performed. Excess enzyme conjugate is again removed by washing 


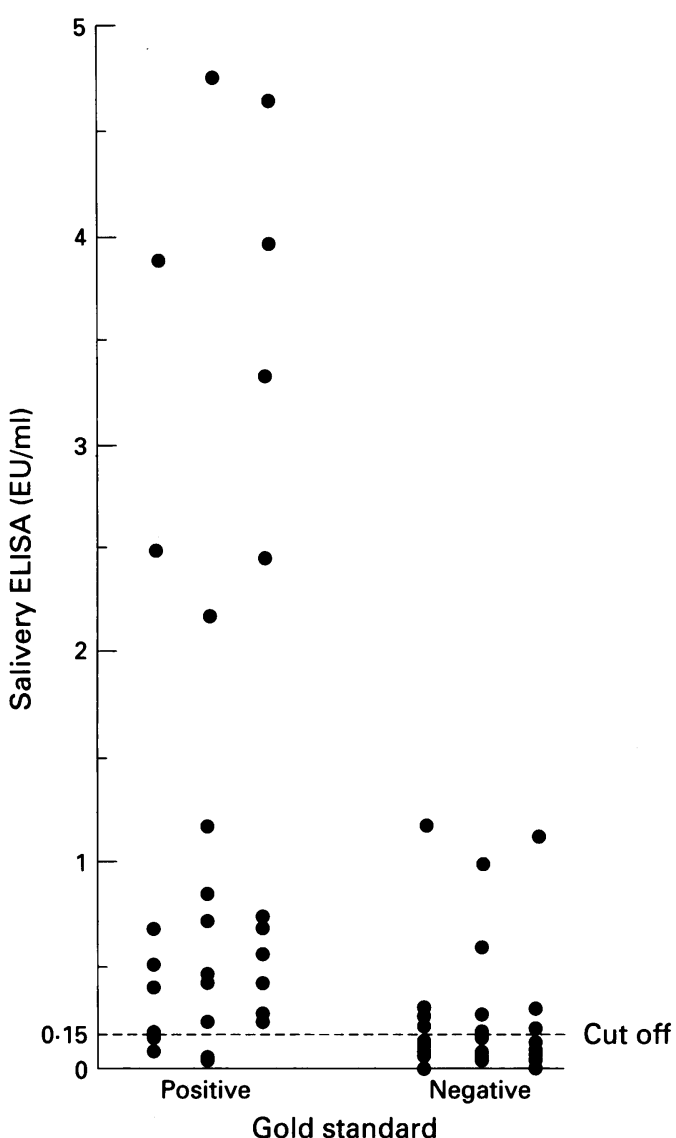

Figure 1: Salivary ELISA values in patients with or without gold standard evidence of $\mathrm{H}$ pylori.

and a substrate solution containing tetramethylbenzidine (TMB) and hydrogen peroxide is added to the wells and incubated for 15 minutes. In the presence of HRP enzyme, TMB gives a blue colour that turns yellow and intensifies on addition of stop solution. The intensity of the colour is proportional to the amount of salivary $H$ pylori (IgG) antibody in the sample. The absorbence value of each assay well is measured in a plate reader (A $450 \mathrm{~nm})$.

A standard curve can be provided using the high standard solution which contains $4 \cdot 0$ ELISA units/ml (EU) of anti- $H$ pylori activity, and sequentially diluting it with dilutent solution to produce a standard curve at suggested concentrates of $4 \cdot 0,2 \cdot 0,1 \cdot 0,0 \cdot 5,0 \cdot 25$ ELISA units. A quantitative assay can then be performed by plotting mean absorbence values against ELISA unit values of the standard curve.

\section{Results}

Thirty two of 86 patients endoscoped were $H$ pylori positive by either urease test, culture

Performance characteristics of saliva and serum antibody ELISA test

\begin{tabular}{|c|c|c|c|c|c|c|c|c|}
\hline & & & \multicolumn{2}{|c|}{ Gold standard } & \multirow[b]{2}{*}{ Sensitivity } & \multirow[b]{2}{*}{ Specificity } & \multirow[b]{2}{*}{$P P V$} & \multirow[b]{2}{*}{$N P V$} \\
\hline & & & $+v e$ & $-v e$ & & & & \\
\hline \multirow{5}{*}{$\begin{array}{l}\text { Saliva } \\
\text { test }\end{array}$} & $\begin{array}{l}0 \cdot 15 \mathrm{EU} / \mathrm{ml} \\
\text { Cut off }\end{array}$ & $\begin{array}{l}+ \text { ve } \\
- \text { ve }\end{array}$ & $\begin{array}{r}28 \\
4\end{array}$ & $\begin{array}{l}15 \\
37\end{array}$ & 88 & 71 & 65 & 90 \\
\hline & $0.3 \mathrm{EU} / \mathrm{ml}$ & + ve & 22 & 5 & 69 & 90 & 81 & 82 \\
\hline & Cut off & $-v e$ & 10 & 47 & & & & \\
\hline & Serum & $+v e$ & 23 & 11 & 85 & 78 & 68 & 91 \\
\hline & test & $-v e$ & 4 & 40 & & & & \\
\hline
\end{tabular}

$\mathrm{PPV}=$ positive predictive value, $\mathrm{NPV}=$ negative predictive value. or histology. In the $H$ pylori positive group, there were four patients with duodenal ulceration and one case of gastric ulceration. There was one case of superficial duodenal ulceration and no cases of gastric ulceration in the $H$ pylori negative group.

In the group of 86 patients, not all gave both blood and saliva and therefore, in the analysis there is a small discrepancy in the total number of salivary tests compared with serum tests.

The mean (SD) salivary IgG titre for $H$ pylori positive and negative patients was $1.16(1.46)$ and $0.171(0.251)$ respectively. These results are significantly different with $\mathrm{p}$ value of less than $0 \cdot 005$. The mean (SD) serum IgG titre for $H$ pylori positive and negative patients was $5.02(4.03)$ and $0.68(0.92)$ respectively, which is also significantly different $(p>0.005)$. Figure 1 shows the EU values for the saliva samples. The Table shows the sensitivity and specificity of the salivary IgG assay with alternative cut off values for the test $(0.15$ and $0.30 \mathrm{EU} / \mathrm{ml})$ along with the results of the serum test. Figure 2 shows the changes in sensitivity and specificity for different cut off values of the ELISA salivary test. The optimal cut off point of $0.15 \mathrm{EU} / \mathrm{ml}$ gave a sensitivity of $88 \%$ and a specificity of $71 \%$, with a negative predictive value of $90 \%$. The sensitivity and specificity for the serum test was $85 \%$ and $78 \%$ at $1.0 \mathrm{EU} / \mathrm{ml}$ cut off (the manufacturer's recommended cut off), with a positive predictive value of $68 \%$ and a negative predictive value of $91 \%$.

On review of the histology, five of 15 false positive saliva tests had histology suggestive of either present or past $H$ pylori infection (chronic active gastritis, lymphoid aggregation, and intestinal metaplasia), although $H$ pylori infection was not seen. Including these patients as $H$ pylori positive gives the saliva test a sensitivity of $89 \%$ and specificity of $79 \%$.

The study was conducted by assessing consecutive patients attending the endoscopy department without any exclusion criteria. However if patients who were taking omeprazole or who had taken recent antibiotics are excluded from the analysis the saliva test has an improved sensitivity of $88 \%$ and specificity of $79 \%$ at the $0.15 \mathrm{EU}$ cut off.

The overall prevalence of $H$ pylori in all ages was $40 \%$ in our study. The changes in positive predictive value and negative predictive value for the salivary ELISA test can be calculated for different prevalences of $H$ pylori and is shown in Figure 3. The test performs best at a prevalence of around $55 \%$.

\section{Discussion}

In this study we compared salivary and serum $H$ pylori IgG ELISA with histological and culture evidence of $H$ pylori colonisation of the antral mucosa. For the saliva test, a cut off value of $0.15 \mathrm{EU} / \mathrm{ml}$ gave the best results with a sensitivity of $88 \%$, although the specificity was poor at $71 \%$. At this cut off the test only failed to detect four $H$ pylori positive patients, which were also missed by the serum test. There were a large number of false positive 


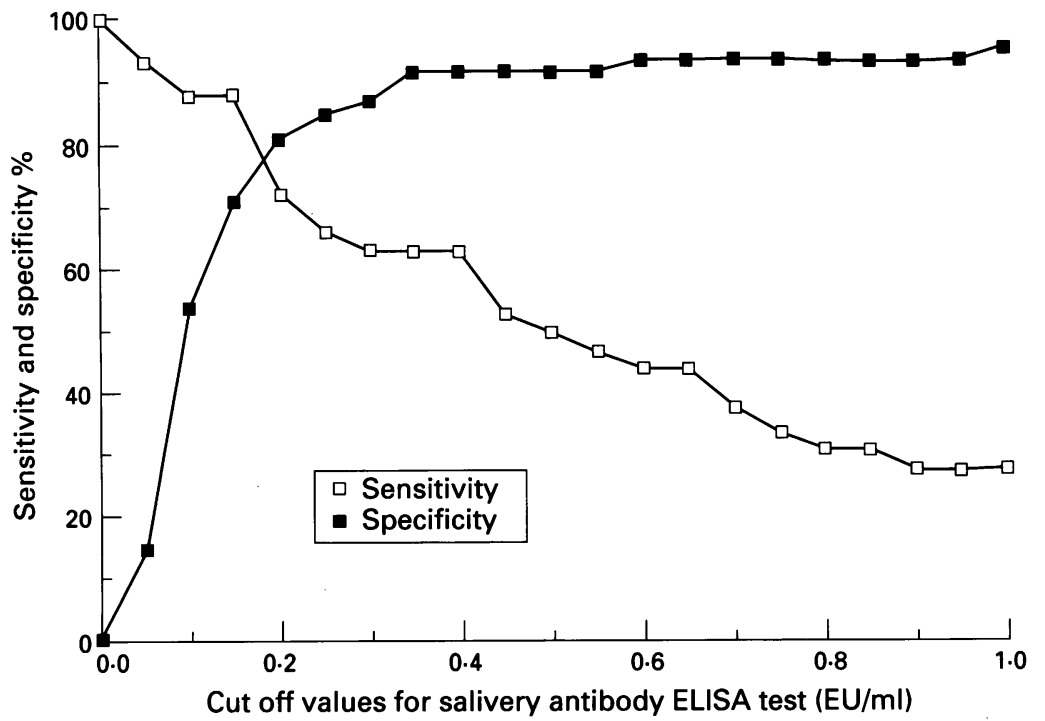

Figure 2: Changes in sensitivity and specificity with different cut off values for the $\mathrm{H}$ pylori saliva serology test. been inadvertent) may remain antibody positive but be biopsy negative for $H$ pylori for at least six months after treatment. ${ }^{10}$ Reviewing the hospital notes, five of the patients with false positive results had documented antimicrobials active against $H$ pylori prior to endoscopy. Fourthly, three of the patients with false positive results were receiving longterm omeprazole treatment, which can suppress the levels of $H$ pylori and make detection more difficult. Our study was designed to assess the use of the saliva test in a district general endoscopy service and there were no exclusion criteria for patients. However inclusion of patients who have received recent antibiotics or are taking omeprazole in a validation study would tend to bias against the test. Fifthly, periodontal disease where capillary permeability is increased or gum bleeding can lead to high titres of salivary IgG and thus to false high readings for IgG to $H$ pylori. ${ }^{11}$

Although the specificity of the saliva test improves at the $0.3 \mathrm{EU} / \mathrm{ml}$ cut off value, the sensitivity of the test at this value of $69 \%$ renders the test inadequate for practical purposes. At the $0.15 \mathrm{EU} / \mathrm{ml}$ cut off value, the negative predictive value of $90 \%$ does give the saliva test a useful place for screening in general practice. A negative saliva test would indicate lack of $H$ pylori colonisation, making peptic ulcer disease unlikely in the young dyspeptic patient and reducing the need for endoscopy. ${ }^{7}$ Indeed the saliva test detected all cases of duodenal ulceration in our study.

Our serum results compare similarly with other commercial tests for $H$ pylori IgG antibody detection. ${ }^{12}$ The sensitivity of the saliva test $(0 \cdot 15 \mathrm{EU} / \mathrm{ml})$ and serum test is similar. The sensitivity of the test may be improved by modification of the antigen. Generally the use of single purified antigens such as urease or the $120 \mathrm{KDa}$ surface protein are very specific but have lower sensitivity. This is because the antibody response to any single antigen is variable from patient to patient. Indeed a small number of patients will never produce a circulating antibody response to $H$ pylori. The better specificity of the serum test makes it the superior test and therefore the gold standard serological test in the hospital setting. In many ways this is to be expected as the concentration of immunoglobulins in saliva is much lower than in serum. ${ }^{13}$ Further development of the salivary assay, which takes into account the relative proportion of $H$ pylori specific IgG to total IgG could improve the performance of the test especially helping to distinguish false high results because of periodontal disease. ${ }^{14}$ More sensitive assays for viral antibodies in saliva have been performed using IgG capture radioimmunoassays (GACRIA), which have been shown to be superior to enzyme linked immunosorbent assays in the detection of salivary IgG to hepatitis A and B, HIV, and rubella virus. ${ }^{15}$ Modification to the test reported here has now been incorporated into the tests to improve its efficiency, using the cut off of $0.15 \mathrm{EU} / \mathrm{ml}$.

Saliva has the advantage of being easier to collect and store, lending itself to widespread
Figure 3: Projected changes in the predictive values of the saliva test with different prevalences of $\mathrm{H}$ pylori. 
use in the community and in epidemiological studies. It would be useful for studies in children where screening with serum would be more difficult. Unlike serum, which needs to be separated within a few hours from blood cells, saliva samples could be collected and posted and batched for up to a month before testing.

The sensitivity of this saliva test is the same as that recently described by Patel. ${ }^{16}$ However, the prevalence of $H$ pylori in their study was $50 \%$, near to the optimum for both tests. Our study was undertaken in an endoscopy population in which the prevalence of $H$ pylori was $40 \%$. As the prevalence of $H$ pylori would be expected to be lower in general practice than an endoscopy population the negative predictive value of the test in this setting should be higher making it a valuable screening test in this setting - but the positive predictive value would be much lower (Fig 3). Although our test detected all patients with peptic ulceration we would still suggest that not only the test be modified to improve its specificity but that further work is done to evaluate its predictive value in general practice to determine the role of such a test in patient management and screening.

We thank the endoscopy and public health laboratory staff for the extra work involved in collecting and processing specimens. This study was sponsored by Cortecs, UK.

1 Warren J, Marshall B. Unidentified curved bacillus on gastric epithelium in chronic active gastritis. Lancet 1983 i: $1273-5$.
2 Barthel JS, Everett ED. Diagnosis of Campylobacter pylori infections: the 'gold standard' and the alternatives. Rev Infect Dis 1990; 12: S107-14.

3 Perez-Perez GI, Dworkin BM, Chodes JE, Blaser MJ. Campylobacter pylori antibodies in humans. Ann Intern Med 1988; 109: 11-7.

4 Wyatt JI, Rathbone BJ. The role of serology in the diagnosis of Campylobacter pylori infection. Scand $\mathcal{F}$ Gastroenterol 1989; 24: S27-34.

5 Goodwin CS, Blincow E, Peterson G, Sanderson C, Cheng W, Marshall B, et al. Enzyme-linked immunosorbent assay for Campylobacter pyloridis: correlation with the presence of $\mathrm{C}$ pyloridis in the gastric mucosa. 7 Infect Dis 1987; 155: 488-94.

6 Veenendall RA, Pena AS, Meijar JL, Endtz $\mathrm{H} \mathrm{Ph}$, van der Est MMC, van Duijn W et al. Longterm serological surveillance after treatment of Helicobacter pylori infecsurveillance after treatment
tion. Gut 1991; 32: 1291-4.

7 Sobala GM, Crabtree JE, Pentith JA, Rathbone BJ, Shallcross TM, Wyatt JI, et al. Screening dyspepsia by

8 Christie J, Codling B, Valori R. Gastric cancer below the age of 55 is rare and is not worth screening for. Gut 1994;35 (suppl 2): S24.

9 McNulty CAM, Dent JC, Uff JS, Gear MWL, Wilkinson SP. Detection of Campylobacter pylori by the biopsy urease test: an assessment of 1445 patients. Gut 1989; 30: 1058-62.

10 Glupczynski Y, Burette A, Goossens H, DePrez C, Butzler JP. Effect of antimicrobial therapy on the specific serological response to Helicobacter pylori infection. Eur $\mathcal{F}$ Clin Microbiol Infect Dis 1992; 7: 583-8.

11 Perry KR, Parry IV, Mortimer PP, Peters TJ. The influence dental status on the detection of IgG class antiviral antidental status on the detection of IgG class antiviral anti-
bodies in human saliva. Arch Oral Biol 1991; 36: 221-6.

12 Jensen AKV, Andersen LP, Wachmann CH. Evaluation of eight commercial kits for Helicobacter pylori IgG antibody detection. APMIS 1993; 101: 795-801.

13 Shillitoe EJ, Lehner T. Immunoglobulins and complement in crevicular fluid, serum and saliva in man. Arch Oral Biol 1972; 17: 241-7.

14 Parry JV, Perry KR, Mortimer PP. Sensitive assays for viral antibodies in saliva: an alternative to tests on serum. Lancet 1987; ii: 72-5.

15 Perry KJ, Brown DWG, Parry JV, Panday S, Pipkin C, Richards A. Detection of measles, mumps and rubella antibodies in saliva using antibody capture radioimantibodies in saliva using antibody cap
munoassay. $\mathcal{F}$ Med Virol 1993; 40: 235-40.

16 Patel P, Mendall MA, Khulusi S, Molineaux N, Levy J, Maxwell JD, et al. Salivary antibodies to Helicobacter pylori: screening dyspeptic patients before endoscopy. Lancet 1994; 344: 511-5. 